\title{
Space current around the earth obtained with Ampère's law applied to the MAGSAT orbit and data
}

\author{
Akira Suzuki ${ }^{1}$ and Naoshi Fukushima ${ }^{2}$ \\ ${ }^{1}$ Faculty of Science and Engineering, Saga University, Saga 840, Japan \\ ${ }^{2}$ Department of Earth \& Planetary Physics, University of Tokyo, Tokyo 113, Japan \\ (Received November 11, 1996; Revised July 22, 1997; Accepted September 30, 1997)
}

\begin{abstract}
An application of Ampère's law to the MAGSAT orbit and data enabled us to study the net space current (total intensity $I$ ) flowing through the plane enclosed by the satellite orbit, and its dependence on the ground magnetic disturbance revealed in the $K p$ - or $A E$-index. Even on magnetically quiet days, MAGSAT often (or sometimes persistently) detected minor or moderate disturbances in the polar regions, in particular inside the auroral oval, without increasing $K p$ - or $A E$-values. Such disturbances are attributable to field-aligned currents into or out of the ionosphere, which produce a magnetic field (of toroidal nature) detectable above the ionosphere associated with a weak magnetic field on the ground, resulting in an occasional poor correlation of $I$ with $K p$ - or $A E$-indices. The calculated $I$-values on quiet days are shown to be the order of $10^{5} \mathrm{~A}$, with a small-range UT variation. During magnetic storms or substorms the $I$-values become one order of magnitude greater, and the net space current is always antisunward, with its intensity roughly proportional to the $A E$-index values. The antisunward space current under the MAGSAT level is the Pedersen current in the ionosphere, and it constitutes the return current of the westward partial ring current (flowing at a distance of several earth radii in the dusk-side magnetosphere) along with the field-aligned currents between the partial ring current and the high-latitude ionosphere in the dayside and nightside hemispheres. The antisunward ionospheric current under the MAGSAT level contributes to a noticeable enhancement in the dawn-dusk asymmetry of the $H$-decrease at MAGSAT level in comparison with the ground data at the developing stage of magnetic storms or substorms.
\end{abstract}

\section{Introduction}

According to Ampère's law, a complete line-integration of the magnetic field tangential to any closed circuit gives the total current $I$ (times $\mu_{0}$ ) penetrating the plane enclosed by the integral circuit, with the relation of

$$
I=\left(1 / \mu_{0}\right) \oint B_{\mathrm{t}} d s,
$$

where $B_{\mathrm{t}}$ is the local magnetic field component tangential to the integral path, and $\mu_{0}\left(=4 \pi \times 10^{-7} \mathrm{H} \cdot \mathrm{m}^{-1}\right)$ is the permeability of the vacuum space.

The magnetic field observed on and above the earth is contributed mainly from the solid earth, and partly from electric currents flowing in the earth's environmental space. The "space current" we named in the present paper consists of (i) the ring current in the magnetosphere, (ii) field-aligned currents into and out of the ionosphere, and (iii) horizontal current in the ionosphere. In the calculation of $I$ with Eq. (1), any magnetic field originating from magnetized bodies or closed electric currents does not contribute at all to the $I$-value, even intense auroral electrojets if their return currents flow entirely in the ionosphere. In the space above the ionosphere, we have to bear in mind the presence of non-potential magnetic field associated with field-aligned currents, which

Copy right $($ The Society of Geomagnetism and Earth, Planetary and Space Sciences (SGEPSS); The Seismological Society of Japan; The Volcanological Society of Japan; The Geodetic Society of Japan; The Japanese Society for Planetary Sciences. produce a toroidal magnetic field with converted horizontal currents in the ionosphere. A model for the coupling of radial and azimuthal current loops is shown in Kan et al. (1990). The toroidal magnetic field thus formed exists in and above the ionosphere, and it scarcely leaks down to the ground.

The MAGSAT operation in 1979-1980 afforded us an ideal opportunity to apply Ampère's law to calculate the total intensity of net space current under the satellite orbit, overcoming the following practical constraints that (1) the magnetic field cannot be known simultaneously at all points along the satellite orbit, but it takes about 1.5 hours to complete its measurement over an entire MAGSAT orbit, and (2) the earth rotates eastward with an angular speed of about $23^{\circ}$ per one revolution of MAGSAT. We already published papers on the net space current under the MAGSAT orbit (Suzuki and Fukushima, 1982, 1984; Suzuki et al., 1985), though our earliest 1982 paper must be discarded due to a lack of the necessary correction for eliminating the spurious effect arising from the earth's rotation (see the last paragraph of Section 2). In the meantime the accuracy of our numerical analysis was improved, and it became possible to compare the space current behaviours on quiet days, disturbed days, and during substorms.

\section{MAGSAT Orbit and Method of Analysis}

The MAGSAT was launched on October 30, 1979, and it remained in orbit over 7 months. The magnetic tapes we received from NASA contained the in situ vector magnetic 
field data for 180 days from November 2, 1979 to May 11, 1980. We selected therefrom the data of 90 days, mostly quiet and highly disturbed days until April 18, 1980, excluding moderately disturbed days.

MAGSAT was in a sun-synchronous orbit with $96.76^{\circ}$ inclination in the twilight meridian, and its orbit plane deviated slightly from the $06-18 \mathrm{~h} \mathrm{LT}$ plane, so as to intersect the equatorial plane at about $17 \mathrm{~h}$ and $05 \mathrm{~h} \mathrm{LT}$ meridians. The MAGSAT orbit with the highest latitude of $\pm 83^{\circ}$ was inclined towards the sunlit side in the northern hemisphere and towards the night side in the southern polar region, as shown in Fig. 1 with the so-called "auroral zones", here designated as the oval regions with incoming and outflowing field-aligned currents detected by the Triad satellite (taken from figure 13(b) of Iijima and Potemra, 1978). Needless to say, MAGSAT itself contributed very

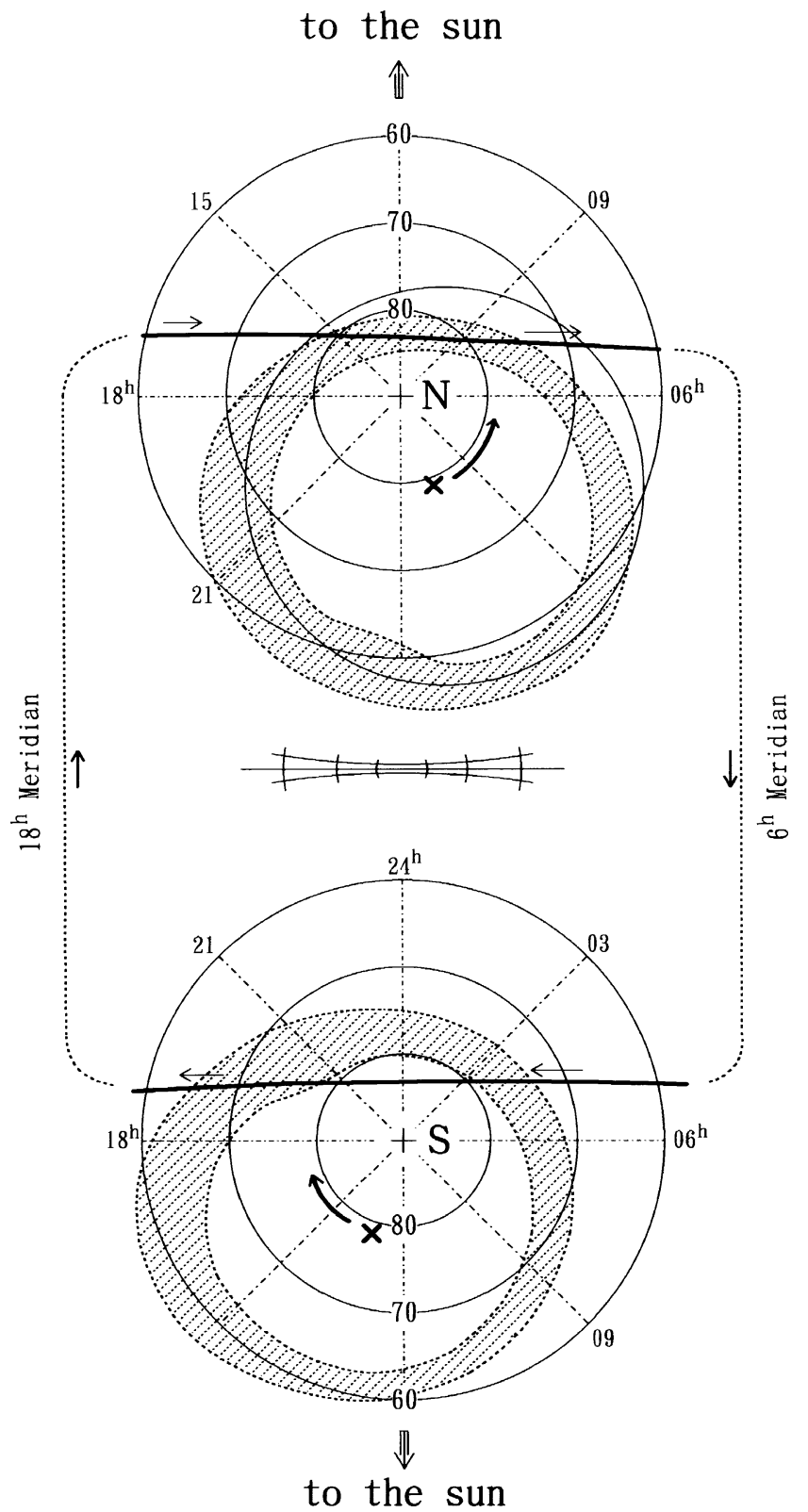

Fig. 1. MAGSAT orbits (thick solid lines) over the polar regions around $06 \mathrm{~h}$ UT. The geomagnetic poles $(\times$ marks $)$ rotate around the geographic pole eastward with time along with the hatched auroral ovals. much to our knowledge on the pattern of magnetic field disturbances recorded above the ionosphere associated with field-aligned currents at high latitudes (e.g., Bythrow and Potemra, 1983; Zanetti et al., 1983; Engebretson et al., 1984; Iyemori et al., 1985; Barfield et al., 1986; Fujii and Iijima, 1987), including $B_{y}$-dependent and northward IMF-related NBZ currents inside the ordinary auroral oval (Iijima et al., 1984; Zanetti et al., 1984; Iijima and Shibaji, 1987).

The apogee and perigee of the MAGSAT were 561 and $352 \mathrm{~km}$ above the earth, respectively, at the initial stage of the satellite operation, with gradual descent with time. The revolution period of MAGSAT was 93 minutes after the launch, and it was reduced finally to 91 minutes. Figure 2 shows two MAGSAT orbits above the rotating earth, one on November 5, 1979 (a week after the launch), and the other on April 13, 1980 (at the last stage of the interval of our data analysis). A gradual latitudinal shift of the apogee and perigee of MAGSAT is resulted from its rotation around the spheroidal earth (Langel, 1982; Langel et al., 1982).

The method of our analysis was reported in our earlier papers, so that only a brief summary is given below. The satellite measured vector magnetic fields as frequently as every $1 / 16$ second, in other words with a spatial distance of about $450 \mathrm{~m}$ over the entire earth. We calculated first one second average values of the observed magnetic field component tangential to the satellite orbit (which are denoted here by $B_{\mathrm{t} 0}$ ), and we substracted the contribution from the global magnetic field derived from the MGST(4/81) model (denoted here by $B_{\mathrm{tm}}$ ), so that we can write here as

$$
B_{\mathrm{t}}=B_{\mathrm{t} 0}-B_{\mathrm{tm}} .
$$

In order to calculate the $I$-value with Eq. (1), the integrand can be either $B_{\mathrm{t}}$ or $B_{\mathrm{t} 0}$ of Eq. (2) along the closed MAGSAT orbit, because the $B_{\mathrm{tm}}$-integration is to vanish due to the curlfree nature of the magnetic field of $B_{\mathrm{tm}}$.

Due to the earth's eastward rotation under the MAGSAT

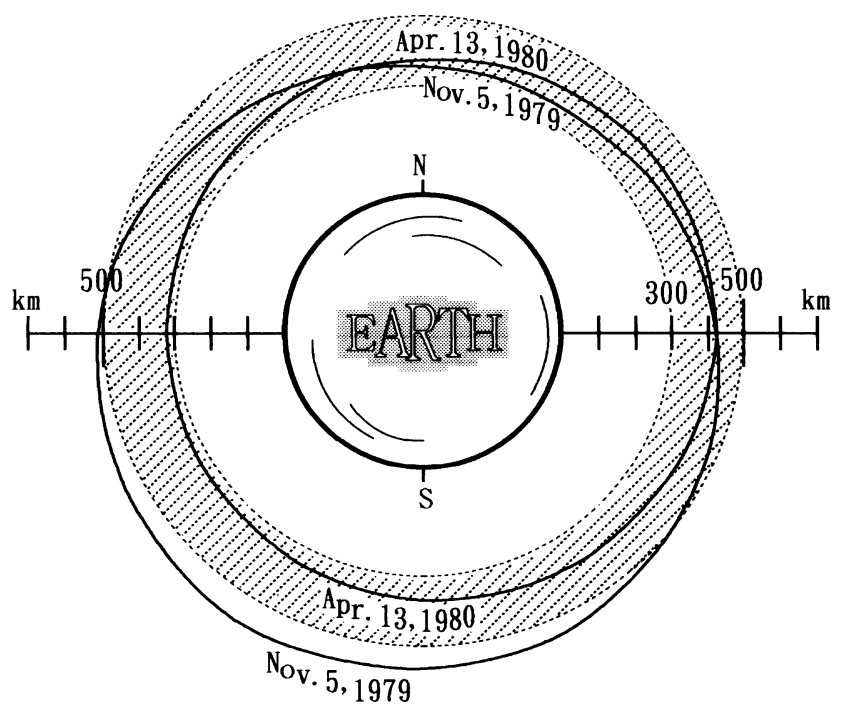

Fig. 2. MAGSAT heights above the rotating earth at the beginning (Nov. 5,1979 ) and the ending (Apr. 13, 1980) of the satellite operation. The height range of $300-500 \mathrm{~km}$ is hatched. 
orbit, the sub-satellite locus of each MAGSAT orbit on the rotating earth crosses the preceding locus near the highest latitude of about $83.2^{\circ}$ in the northern and southern polar regions (see figure 5 of Suzuki et al. (1985) paper, or figure 2 of Suzuki and Fukushima (1984) paper), and these crossing points are taken as the starting and ending points for the $B_{\mathrm{t}^{-}}$ integration along every orbit of MAGSAT. The choice of these terminal points will contribute hopefully to minimizing the error in the numerical $B_{\mathrm{t}}$-integration, because both $B_{\mathrm{t} 0}$-and $B_{\mathrm{tm}}$-values are minimum there along every MAGSAT orbit. We adopted both the northern and southern highestlatitude terminal points as the starting points for the lineintegration of $B_{\mathrm{t}}$, so that the latter half of an integration path overlaps with the former half of the next path, so as to double the total number of the integral paths.

In the calculation of $I$ with Eq. (1), the integrand is the scalar product of $B_{\mathrm{t}}$ and $d s$. $B_{\mathrm{t}}$-vectors (to the direction of MAGSAT flight in the inertial space) are not always parallel to $d s$ (composing the MAGSAT loci on the rotating earth), although the angle between $B_{\mathrm{t}}$ and $d s$ is in fact very small, amounting at most to $3.6^{\circ}$ on the equator. If the calculation of $I$ is carried out with $\left|B_{\mathrm{t}}\right| \cdot|d s|$, instead of $B_{\mathrm{t}} \cdot d s$, the calculated $I$-value contains a spurious effect arising from the earth's rotation under the MAGSAT orbit.

\section{Magnetic Field Component along MAGSAT Orbit, $B_{t}$, and Its Latitude Dependence}

Figure 3 shows the latitudinal dependence of the "observed minus MGST(4/81)-model values" of the geomagnetic field component tangential to the MAGSAT orbit, i.e., $B_{\mathrm{t}}$-values, on

(a) a very quiet day of November 5, 1979 $\left(K p=0_{+}, 0_{0}, 0_{+}, 1_{-}, 1_{0}, 1_{-}, 1_{0}, 0_{+}\right)$,

(b) a disturbed day of November 13, 1979

$\left(K p=4_{0}, 5_{-}, 4_{-}, 4_{+}, 4_{0}, 5_{0}, 5_{+}, 4_{+}\right)$,

(c) a day with substorm on April 6, 1980 $\left(K p=0_{+}, 2_{+}, 1_{+}, 5_{-}, 5_{0}, 5_{0}, 5_{+}, 3_{+}\right)$.

In these three diagrams each horizontal line is a datum line for $B_{\mathrm{t}}$-values for each MAGSAT orbit; its starting and ending UT times are indicated respectively at left- and rightside margins. The left halves of the $B_{\mathrm{t}}$-curves are for the dusk meridian from the southern terminal points, while the right halves are for the dawn meridian from the north polar region back to the initial terminal points in the south polar region. The $B_{\mathrm{t}}$-scales are the same for all diagrams, as indicated for $400 \mathrm{nT}$ range at the top. The $B_{\mathrm{t}}$-values in the diagrams are plotted for every 4 seconds, though 1 -second values were calculated. In middle and low latitudes over the earth, the southward magnetic field is revealed as positive $B_{\mathrm{t}}$-values in the dawn meridian and as negative $B_{\mathrm{t}}$-values in the dusk meridian.

Taking a glance at three diagrams in Fig. 3, we notice immediately the following characteristics of $B_{\mathrm{t}}$-curves, namely:

(1) On a very quiet day of November 5, 1979, shown in Fig. 3(a), and during quiet interval of April 6, 1980 shown in the top half of Fig. 3(c), small $B_{\mathrm{t}}$-fluctuations (less than $400 \mathrm{nT}$ in range) were detected only near the northernmost and southernmost regions of the MAGSAT orbit, and not at all in the auroral zone. The observed fluctuations were generally of greater amplitude in the southern (summer) hemisphere than in the northern (winter) hemisphere. Iijima et al. (1984), Zanetti et al. (1984), and Iijima and Shibaji (1987) discovered the existence of NBZ (meaning "Northward Bz") field-aligned currents inside the auroral zone in the polar region when the interplanetary magnetic field was northward.

(2) During magnetic disturbances including substorms, $B_{\mathrm{t}}$-curves are characterized by a distinct appearance of a pair of horns (separated by $4500 \pm 1000 \mathrm{~km}$ ) with superimposing rapid fluctuations at high latitudes in both the northern and southern polar regions, as shown in Figs. 3(b) and 3(c). The locations of these horns show a systematic diurnal variation in geographic latitude with Universal Time; the lowest and highest latitude of the leading horns is seen respectively around $23 \mathrm{~h}$ and $11 \mathrm{~h} \mathrm{UT}$ in both the northern and southern polar regions. Figure 4 illustrates the UT dependence of the MAGSAT paths on a map with fixed positions for the auroral zones and the geomagnetic axis poles (marked by $\times$ ), with the geographic poles (marked by + ) rotating around the geomagnetic poles once a day. The UT dependence of $B_{\mathrm{t}}$-horn latitudes revealed in Figs. 3(b) and 3(c) can be reasonably explained by means of Fig. 4.

(3) The shapes of $B_{\mathrm{t}}$-horns with superimposing rapid fluctuations recorded for consecutive MAGSAT orbits (with the repetition period of about 1.5 hours) during magnetic disturbances are generally rather different one another. In the four columnar series of $B_{\mathrm{t}}$-horns in Fig. 3(b), only the negative $B_{\mathrm{t}}$-excursions on the dusk side in the northern polar region maintain nearly the same form for consecutive MAGSAT orbits throughout the day. This would mean that the geomagnetic disturbance in the northern auroral zone on the dusk side seemed to be rather steady throughout a disturbed day of November 13, 1979.

(4) On the other hand, $B_{\mathrm{t}}$-horns with rapid fluctuations observed generally on the dawn side often show quite different shapes for consecutive MAGSAT orbits, as are clearly seen in Figs. 3(b) and 3(c). For example, during 11$18 \mathrm{~h}$ UT on November $13,1979, B_{\mathrm{t}}$-horns on the dawn side in the north polar region changed from an intense positive pulse in a narrow region to a very low-level disturbance, followed by an intense negative pulse in a narrow region, a broad negative excursion over a wide area, and then an oscillation of moderate magnitude. In Fig. 3(c) we see in the dawn-side auroral zone in the north polar region an extraordinarily intense negative $B_{\mathrm{t}}$-spike for 2 hours or so during the substorm on April 6, 1980. The poor correlation between these consecutive $B_{\mathrm{t}}$-curves will indicate that the geomagnetic disturbance observed in the auroral zones on the dawn side seems to be extremely variable with time, in other words sporadic, in contrast to the magnetic disturbance on the dusk-side in the northern hemisphere observed on November 13, 1979, when the northern polar region was in the dark hemisphere.

(5) At middle and low latitudes, $B_{\mathrm{t}}$-curves are usually very smooth, not only on quiet days but also on disturbed days or during magnetic substorms. Since $B_{\mathrm{t}}$ picks up only the magnetic field component in the direction of MAGSAT flight, it is unaffected by the east-west toroidal magnetic field in the dusk-side ionosphere in the north and south of the 
\begin{tabular}{|lllll}
\hline NOV. & 05,1979
\end{tabular}$\quad$ I $400 \mathrm{nT}$
$83 \mathrm{~S}$
$\mathrm{EQ}$
$83 \mathrm{~N}$
EQ
$83 \mathrm{~S}$

0.68

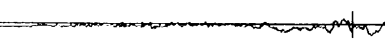

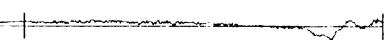

2. 23

2. 25 tom

3. 80

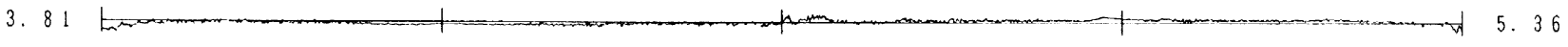

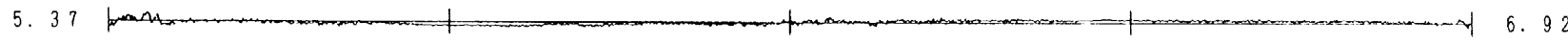

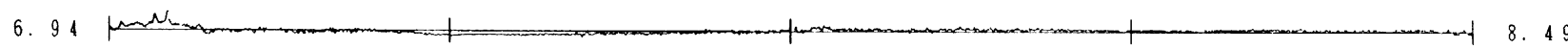

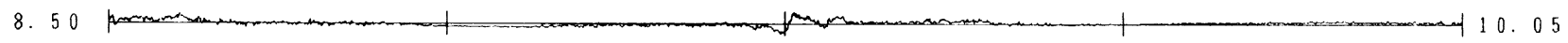

10.06 06

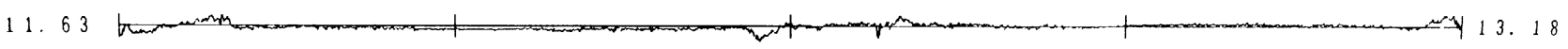

13. 19 |

14. $75 \mathrm{FH}$

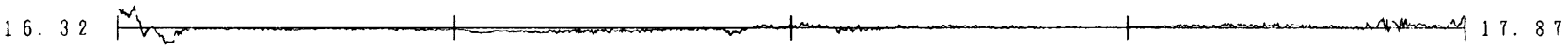

17.88

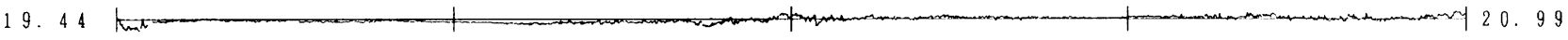

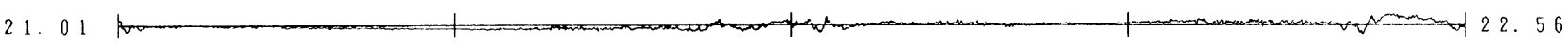

22. 57 A

(a)

Fig. 3. $B_{\mathrm{t}}$-variations on (a) Nov. 5, 1979, a quiet day, (b) Nov. 13, 1979, with moderate disturbance throughout a day, and (c) April 6, 1980, a day with a severe substorm. The sensitivity scale is common to all three days, as shown at the top of the diagrams. Each row is for one closed orbit, starting and ending at UT indicated at the left and right margins.

magnetic dip equator (discovered by Maeda et al., 1982, 1985).

(6) On disturbed days, $B_{\mathrm{t}}$-deviations from the datum line at middle and low latitudes are much greater than on quiet days, and they are always positive on the dawn side and negative on the dusk side, meaning that a southward magnetic field is observed on both the dawn and dusk sides of the earth at middle and low latitudes. We notice in Fig. 3(b) that negative $B_{\mathrm{t}}$-deviations in the dusk meridian observed by MAGSAT above the ionosphere are usually greater in 


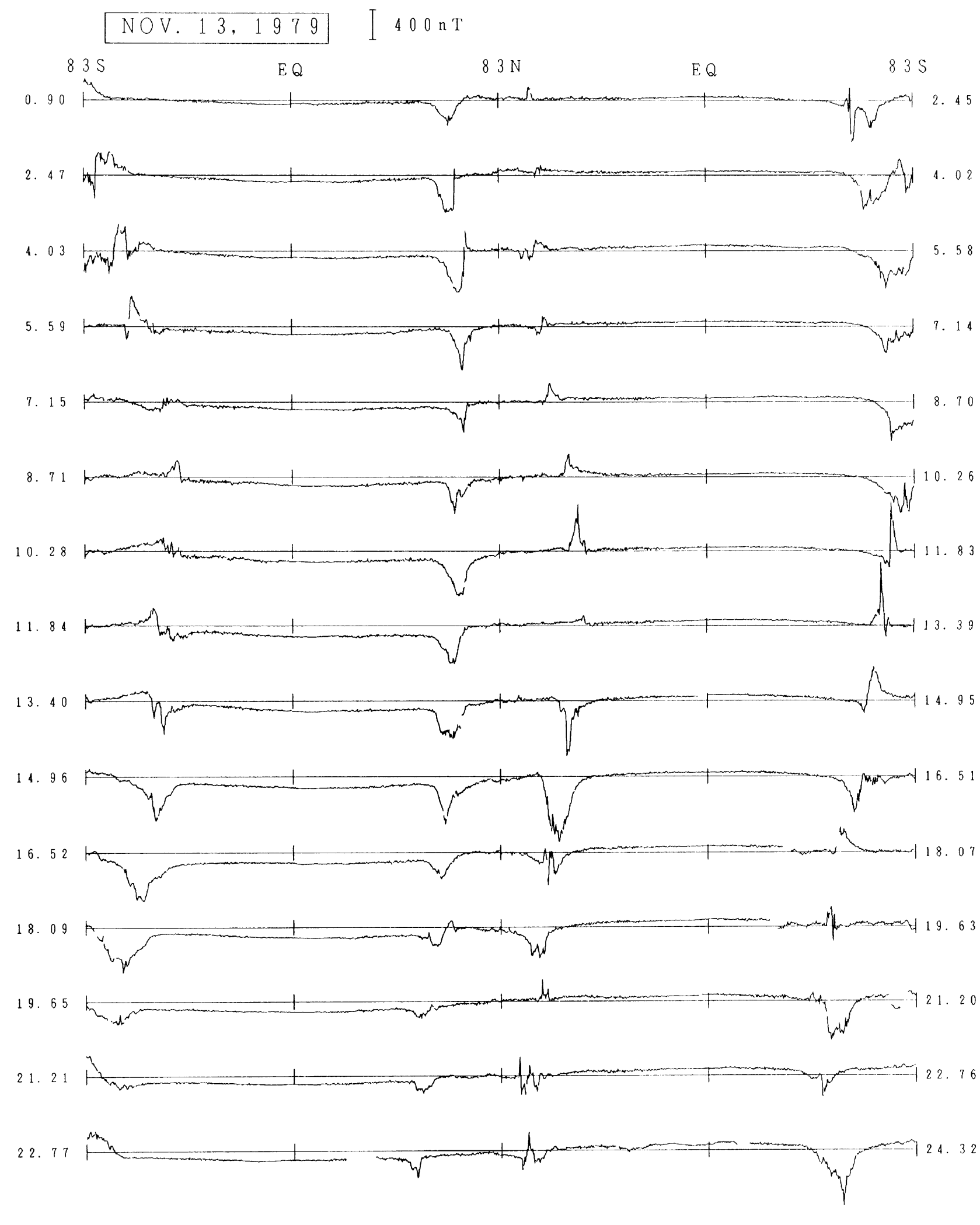

(b)

Fig. 3. (continued)

magnitude in comparison with positive ones in the dawn meridian. A similar dawn-dusk asymmetry of $B_{\mathrm{t}}$-deviations is perceivable also on quiet days, though small in magnitude.

(7) The contribution to $B_{\mathrm{t}}$-values at high latitudes originates to a considerable extent from the fact that the MAGSAT paths are not perpendicular to the field-aligned current sheets along and inside the auroral oval in the polar regions, as is demonstrated in Fig. 1, so that the toroidal magnetic field between the two parallel sheets of field-aligned currents into and out of the ionosphere contributes considerably to $B_{\mathrm{t}}$ 


APR. 06,1980 I $400 \mathrm{nT}$
$83 \mathrm{~S}$
$\mathrm{E} Q$
$83 \mathrm{~N}$
$E Q$
$83 \mathrm{~S}$

0.91

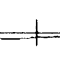

$\sqrt{4}+2$

2. 44

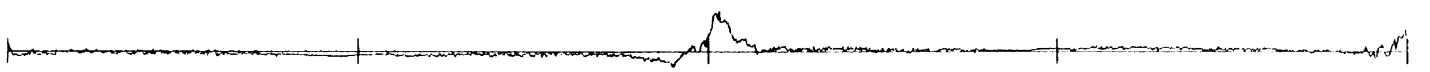

3. 98
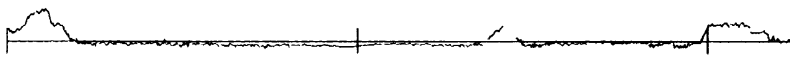

- 5.50

5. 51 porrq
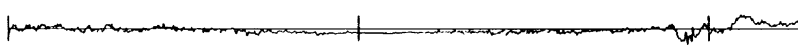

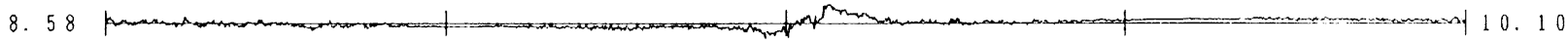
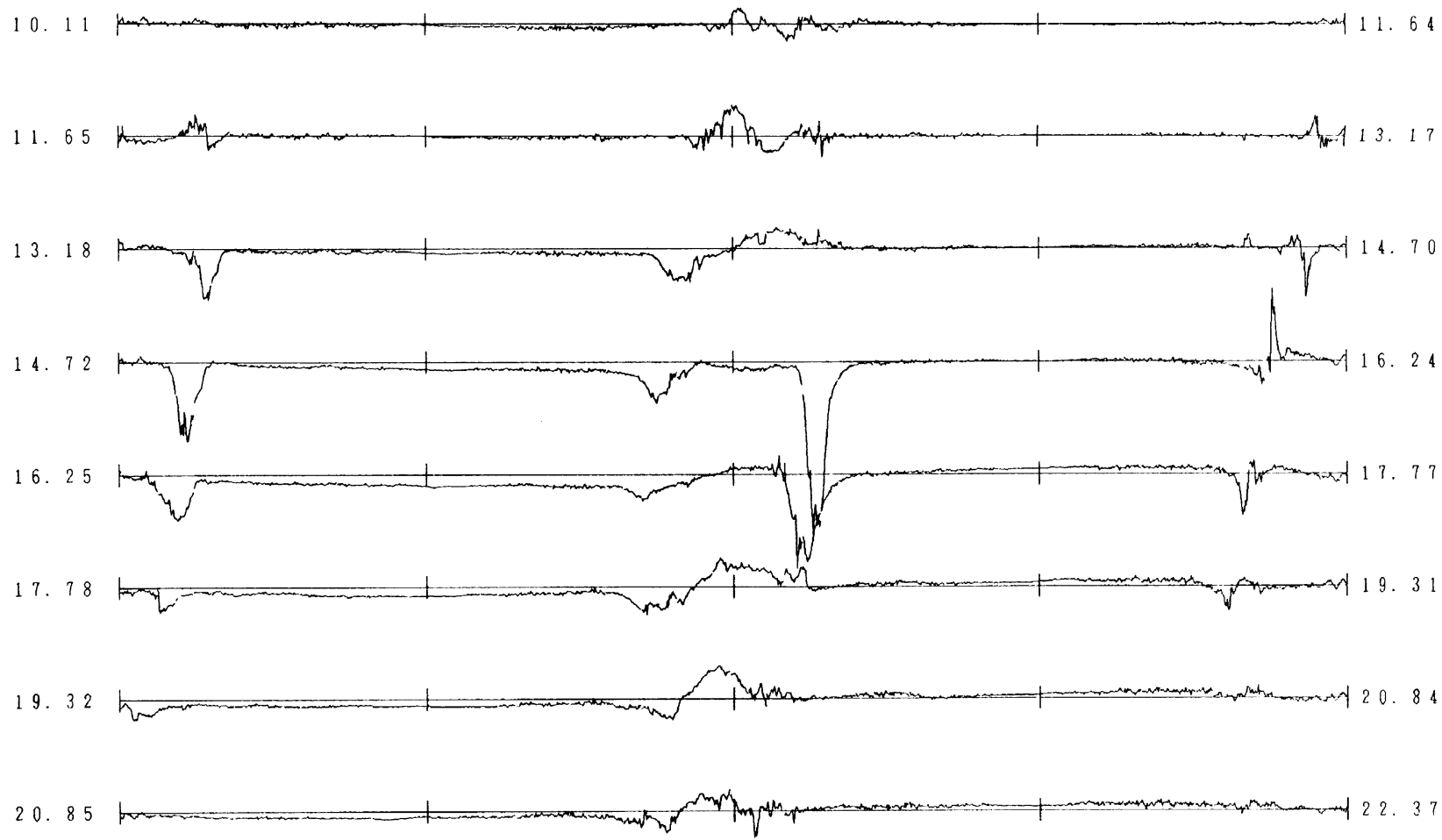

22. 38

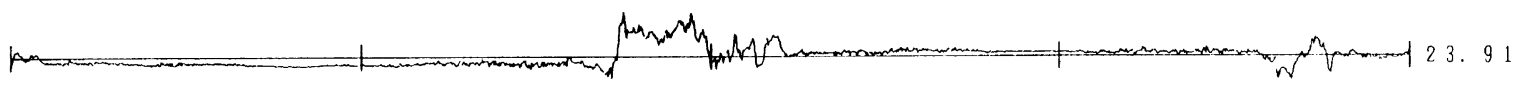

23. 92 pren

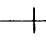

(c)

Fig. 3. (continued).

detected by MAGSAT.

(8) It is interesting to note here that $B_{\mathrm{t}}$-values scarcely exceeded $1000 \mathrm{nT}$ in its absolute magnitude, whereas the geomagnetic disturbance observed on the ground and by
MAGSAT often exceeded $1000 \mathrm{nT}$ in the auroral zone on disturbed days. There are a number of illustrations for great geomagnetic disturbance fields detected at high latitudes by MAGSAT, e.g., in the papers by Hughes et al. (1982), Iijima 


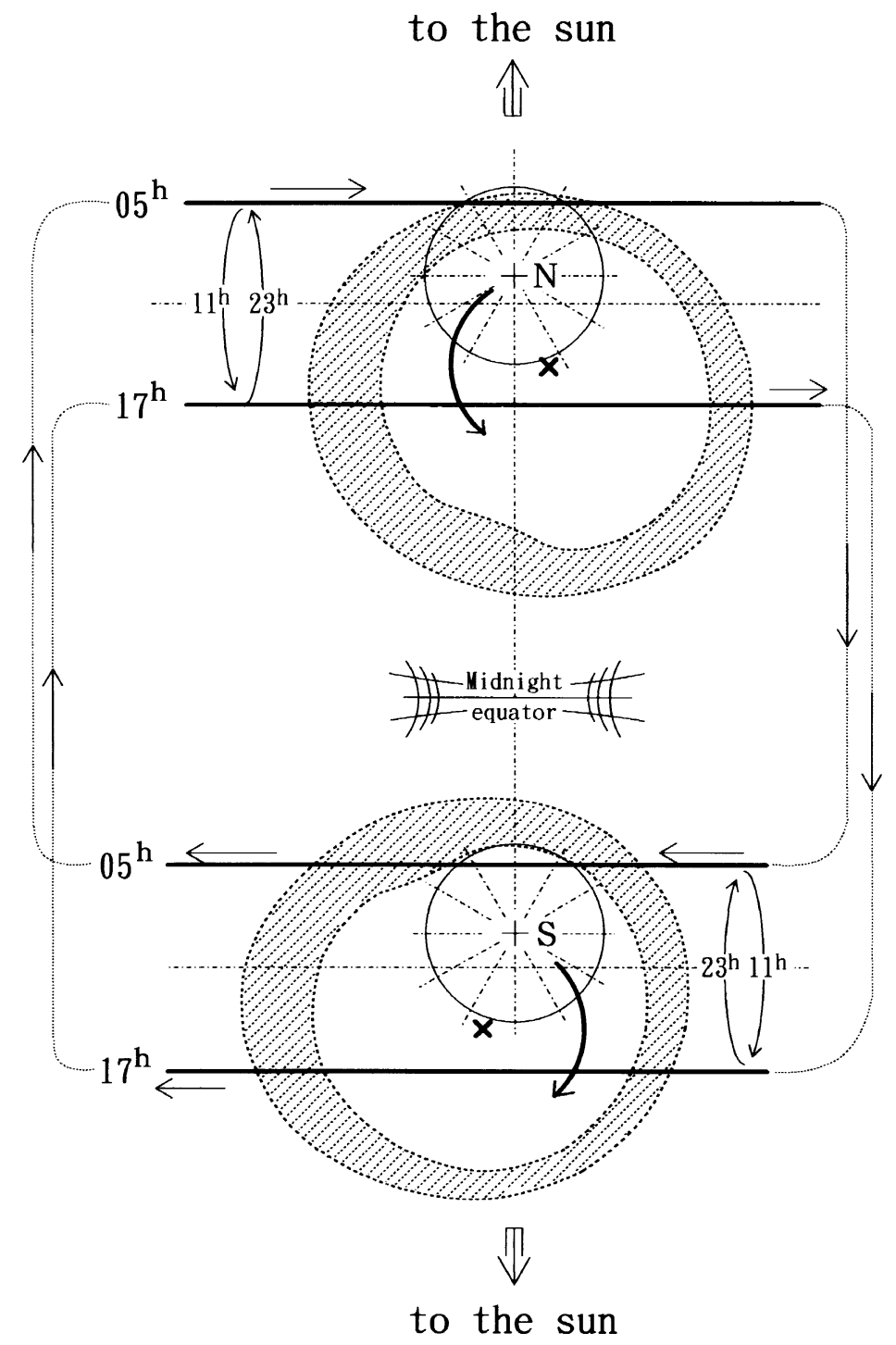

Fig. 4. The MAGSAT orbit trajectories depending on UT shown on the polar maps with fixed positions of the auroral zones; the geographic poles rotate around the geomagnetic poles $(\times$ marks $)$ in these maps.

et al. (1982), Klumpar and Greer (1982), Wallis et al. (1982), Zanetti and Potemra (1982), Zanetti et al. (1982), Kamide et al. (1984), Potemra et al. (1984), Lanchester and Wallis (1985), Barfield et al. (1986), Iijima and Shibaji (1987), Yamauchi and Araki (1989), Iyemori (1990), and Yamada et al. (1990). Figure 6 of Iyemori's (1990) paper gives us an impression that most of great magnetic disturbances at high latitudes are nearly perpendicular to the MAGSAT paths, so that they do not affect $B_{\mathrm{t}}$-curves so much throughout the MAGSAT flight, even though the horizontal component of the geomagnetic field must have been disturbed very often more than $1000 \mathrm{nT}$ at high latitudes. The maximum $B_{\mathrm{t}}$-value we had obtained throughout our analysis was $1500 \mathrm{nT}$, and such great $B_{\mathrm{t}^{-}}$-values were recorded very rarely.

\section{Intensity of the Space Current through the Plane Enclosed by MAGSAT Orbit}

This section deals with the total intensity of space current under the MAGSAT level, i.e., the net sunward or antisunward current passing through the plane enclosed by the satellite orbit, which is denoted by I throughout the present paper, calculated with Ampère's law shown in Eq. (1) in Section 1. Since the MAGSAT flew over the earth with a period of 93-91 minutes, and the numerical integration of $B_{\mathrm{t}}$-values along the satellite orbit was carried out for each path starting from the northernmost and southernmost points of the sub-satellite locus (as explained in Section 2), the calculated values of $I$ are to be interpreted as the average intensity of the net space current under the MAGSAT orbit for every 45.5-46.5 minutes of time. Throughout this paper the sign of $I$ is taken positive for the sunward current, and negative for the antisunward current under the MAGSAT orbit.

Figure 5 shows the calculated current intensities $I$, with small full square marks for every 46.5 minutes intervals, for 8 days (4 quiet and 4 disturbed days) including three typical days shown in Fig. 3 with observed $B_{\mathrm{t}}$-values along individual MAGSAT orbits. The geomagnetic activity on these 8 days is indicated by the $K p$-index values (above the abscissas for each three-hour interval) and the $A E$-indices (given every minute; published by the Data Analysis Center, WDC-C2 for Geomagnetism, Kyoto University, 1986), 


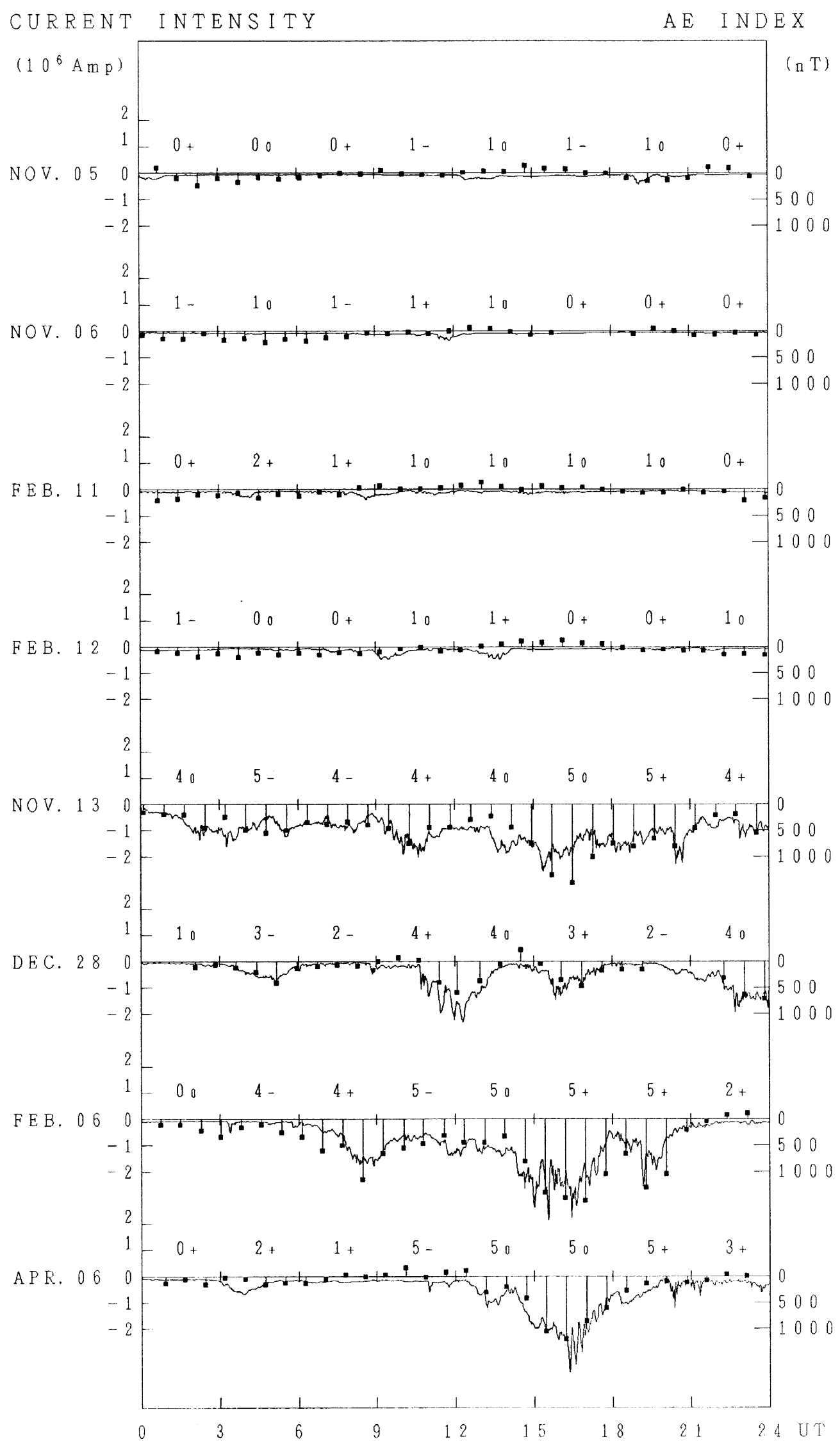

Fig. 5. Intensities of total space currents under the MAGSAT orbit for 4 quiet and 4 disturbed days, shown by full square marks connected with vertical lines. The scale for the current intensity is shown at the left-side ordinate in $10^{6} \mathrm{~A}$. Numeral figures in the diagram are 3-hour $K p$ 's. Curves are $A E$ indices (shown downward positive) with the scale at the right-side ordinate. 
positive downward for the convenience of comparison with all calculated $I$-values.

A simple estimation for the accuracy of $I$ calculation is given here. If $B_{\mathrm{t}}$ is assumed to be within an accuracy of $3 \mathrm{nT}$ everywhere along the MAGSAT orbit, the integrated error for $I$ will be $3 \mathrm{nT} \times 2 \pi \times(6370+$ MAGSAT height $) \mathrm{km} / \mu_{0}$ at most, i.e., $1.2 \times 10^{5} \mathrm{~A}$.

On disturbed days the space current intensity $I$ under the MAGSAT orbit is one order of magnitude greater, i.e., $10^{6}$ $\mathrm{A}$, and it is always negative. The intensity of antisunward space current under the dawn-dusk MAGSAT orbit plane shows a high correlation with the simultaneous $A E$-index values, even on April 6, 1980, with a substorm of only a few hours duration. It is seen in Fig. 5 that $I$ of $10^{6} \mathrm{~A}$ corresponds roughly to $500 \mathrm{nT}$ of the $A E$ index.

Although we see a general parallelism of curves between the $A E$-indices and $I$-values in Fig. 5, there are occasionally some noticeable discrepancies between the calculated $I$ values and the $A E$-curves. For the days shown in Fig. 3, such discrepancies are seen for the $I$-values of the following intervals, i.e.,

Nov. 5, 1979: $I$-values centering at 00.68, 02.24, 03.80, $14.75,15.52$, and 16.31 UT,

Nov. 13, 1979: $I$-values centering at $15.73,16.51$, and

CURRENT INTENS I TY

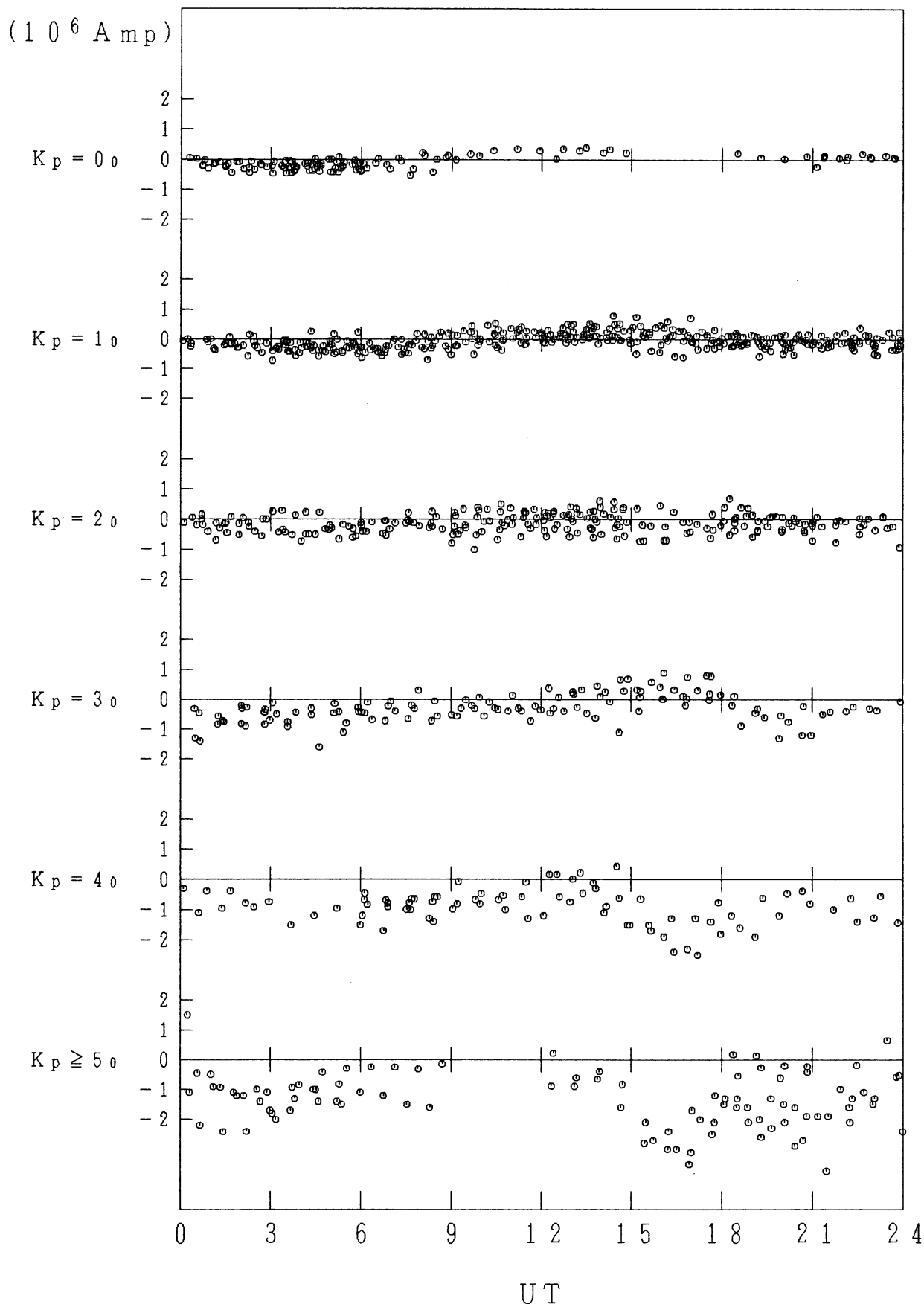

Fig. 6. Calculated intensity of space current under the MAGSAT orbit for $K p$ values of $0_{0}, 1_{0}, 2_{0}, 3_{0}, 4_{0}$, and $\geq 5_{0}$. 


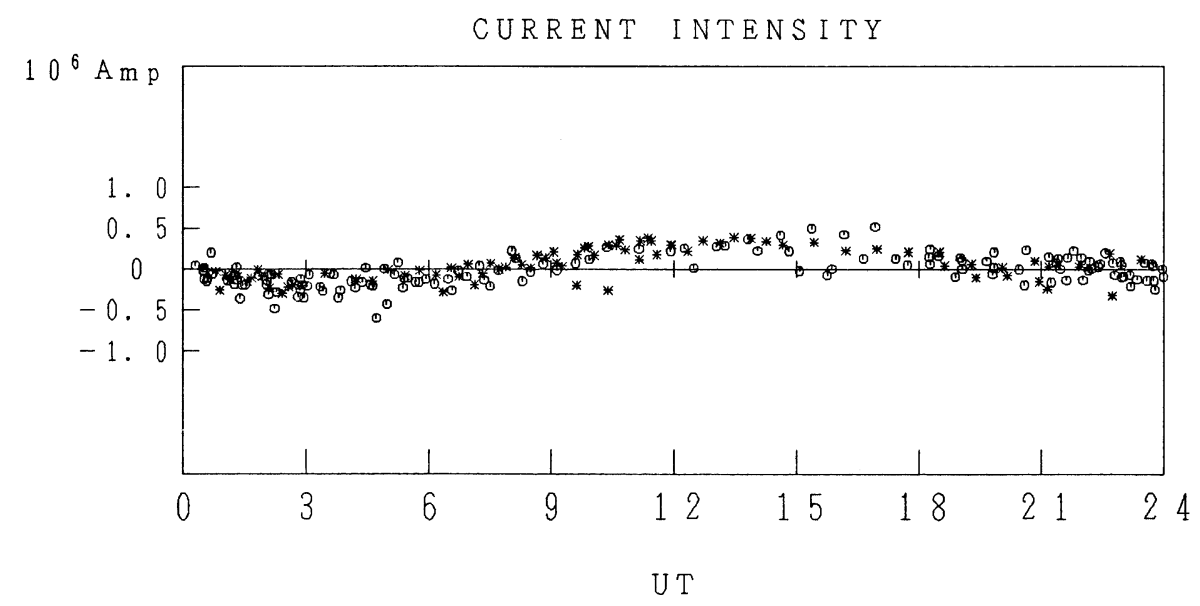

Fig. 7. Space current intensity under the MAGSAT orbit for $K p=0_{0}$ and $0_{+}$days in November-December 1979 (with $\bigcirc$ marks) and March-April 1980 (with * marks). No essential difference is seen between these two groups despite a considerable descent of the MAGSAT apogee after 4 months of the satellite flight.

\subsection{UT,}

Apr. 6, 1980: $I$-values centering at 03.97, 10.10, 11.64, and $12.40 \mathrm{UT}$.

These discrepancies between the calculated $I$-values and the $A E$-index values can be well understood if we scrutinize the original $B_{\mathrm{t}}$-curves (shown in Fig. 3) used for calculating $I$ values. For a quiet day of November 5, 1979, the discrepancies originate from minor disturbances taking place in the northern and southern polar regions. It is also worth noting here that the $I$-values at UT 14-17 hours for all four examples of quiet days shown in Fig. 5 are positive, arising from minor magnetic disturbances over the antarctic area.

On a disturbed day of November 13, 1979, three large amplitude negative $I$-deviations during 15-18 UT are due to a great and broad negative $B_{\mathrm{t}}$-excursion observed at 14961729 UT. On April 6, 1980, we see a positive $B_{\mathrm{t}}$-deviation of a considerable magnitude in the southern polar region around $04 \mathrm{UT}$. It is interesting to point out that an extremely great negative $B_{\mathrm{t}^{-}}$-spike contributed to the large negative $I$ value at the time of the substorm on this day.

Figure 6 shows a composite diagram for the net current intensities under the MAGSAT, for various $K p$-values $\left(0_{0}\right.$, $1_{0}, 2_{0}, 3_{0}, 4_{0}$, and $\geq 5_{0}$ ) from the data of 90 days. We readily notice a diurnal variation in $I$, with a small amplitude, when $K p$-values are small (up to $K p=2_{0}$ ), with a slight negative level around $03-05 \mathrm{~h} \mathrm{UT}$ and a slight positive level around $10-14$ h UT. For $K p$-indices of $4_{0}$ or more, the $I$-value becomes negative almost without exception regardless of hours of a day. Figure 6 gives us an impression that the calculated $I$-values are apparently more sensitive to $\mathrm{Kp}$ values for 15-21 h UT. The calculated $I$-values seem to show a better correlation with the simultaneous $A E$-indices having much higher time-resolution than the three-hour indices $K p$. We have to remember that $K p$ is based simply on the maximum range of magnetic field disturbance (and not the average disturbance) in each three-hour interval observed at 12 designated stations situated at geomagnetic latitudes $47-$ $62^{\circ}$.

It is also checked here whether or not the calculated $I$-values showed a noticeable decrease during the MAGSAT opera- tion with a gradual lowering of the satellite height over the earth. We see from Fig. 2 that the cross-section area enclosed by the MAGSAT orbit above the earth decreased approximately $30 \%$ during the period from November 5 , 1979 to April 13, 1980. Figure 7 shows the $I$-values for quiet periods with $K p=0_{0}$ and $0_{+}$during November-December 1979 and March-April 1980, plotted with different marks in one diagram. We notice no essential difference of the $I$ values for these two groups, despite a considerable descent of the MAGSAT apogee in 4 months. This fact will indicate that the antisunward space current during geomagnetic disturbance seems to flow mostly within $320 \mathrm{~km}$ above the earth, in the ionospheric $E$ and $F$ regions.

Although the diurnal variation in UT of $I$-values on extremely quiet days, revealed in Fig. 7, might suggest a possible presence of space current under the MAGSAT orbit (with its direction fixed to the rotating earth, in this case from the African side to the Pacific side), we must check beforehand very carefully whether or not the MGST(4/81) model was accurate enough to allow us to discuss the reliability on such a weak space current fixed to the earth.

\section{Dawn-Dusk Asymmetry of the Southward Magnetic Disturbance Field at Low Latitudes during Magnetic Storms on the Ground and at the MAGSAT Level}

It has been known for a long time that the southward magnetic disturbance field observed at middle and low latitudes during magnetic storms (denoted hereafter by $\Delta H$ in this paper) shows a noticeable dawn-dusk asymmetry on the ground, greater in the evening than in the morning sector. Before the space age, the dawn-dusk $\Delta H$-asymmetry on the ground was attributed to the eastward (at dawn) and westward (at dusk) currents flowing in the ionosphere. If this interpretation were really correct, the $\Delta H$-asymmetry above the ionosphere would be reversed (i.e., southward $\Delta H$ is $>0$ at dawn and $<0$ at dusk) in contrast to the dawn-dusk $\Delta H$ asymmetry observed on the ground.

Since 1960's, when satellite measurements became popular in space research, the dawn-dusk $\Delta H$-asymmetry has been 
discussed in connection with "partial ring current system", and various models have been proposed, e.g., by Cummings (1966), Crooker and Siscoe (1971, 1981), Crooker and McPherron (1972), Kamide and Fukushima (1972) and others, as reviewed by Fukushima and Kamide (1973). Figure 8 (taken from Suzuki et al. (1985)) is an idealized simple picture for the three-dimensional partial ring current coexisting with a symmetric ring current in the geomagnetic equatorial plane, which consists of the following three segments:

(i) a westward partial ring current of $2 \cdot 10^{6} \mathrm{~A}$ with $180^{\circ}$ longitudinal extent (replaced by a line-current on the equatorial plane on the afternoon side at the geocentric distance of 4 earth radii),

(ii) field-aligned currents in the magnetosphere, replaced by line-currents of $10^{6} \mathrm{~A}$ each in the northern and southern hemispheres in the noon-midnight meridian (although they must be practically current sheets over a wide longitude range), towards and away from the ionosphere on the dayside and the nightside, respectively, and

(iii) antisunward horizontal current of $2 \cdot 10^{6} \mathrm{~A}$ flowing in the ionosphere below the MAGSAT level.

It has been widely accepted that a partial ring current system with the above three segments is favourable to explain the

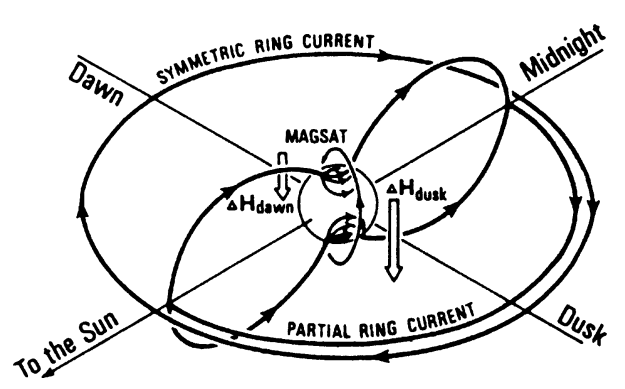

Fig. 8. A model of electric circuit on disturbed days with a partial ring current, which accounts for the observed dawn-dusk asymmetry of the southward magnetic field and the antisunward space current below the MAGSAT level (after Suzuki et al., 1985). dawn-dusk $\Delta H$-asymmetry observed during magnetic storms on the ground at middle and low latitudes.

The dawn-dusk asymmetry of the southward external disturbance field during magnetic storms observed at the MAGSAT level was first reported by Yanagisawa (1984) for the entire period of MAGSAT operation from November 1979 through May 1980. A part of his result is shown here in Fig. 9 (reproduced from Suzuki et al. (1985)), where the top diagram shows the southward magnetic disturbance field at the equator on the dawn and dusk meridians (denoted by E1) measured with MAGSAT. We notice immediately in E1-curves in Fig. 9 that a remarkable dawn-dusk $\Delta H$ asymmetry up to several tens of nT (southward $\Delta H$ is much stronger on the dusk side than on the dawn side) seen only during initial stage of magnetic storms, and the asymmetry seems to disappear in their decaying stage.

\section{Antisunward Current in the Ionosphere as a Possible Contributor to the Enhanced Dawn- Dusk $\Delta H$-Asymmetry above the Ionosphere Observed by MAGSAT}

Among the three segments of the schematic partial ring current system shown in Fig. 8, the segments (i) and (ii) are not capable of producing a marked dawn-dusk $\Delta H$-asymmetry, because they flow in the magnetosphere far from the earth. Suzuki et al. (1985) advocated that the antisunward space current under the MAGSAT orbit, i.e., the segment (iii) of the partial ring current system, would be a possible contributor to the enhanced dawn-dusk $\Delta H$-asymmetry observed at the MAGSAT level.

Figure 10 illustrates the dawn-dusk cross-section of the antisunward current in the ionosphere, if the electric conductivity is simply assumed to be uniform everywhere over the earth. In such a case, the electric currents (fed by fieldaligned currents into the ionosphere on the dayside) spread over the ionosphere uniformly from the points of current injection in the northern and southern sunlit hemispheres, so that the current density at the equator in the dawn-dusk meridian is $\left(2 \cdot 10^{6} \mathrm{~A}\right) /\left(4 \cdot 10^{4} \mathrm{~km}\right)=50 \mathrm{~A} / \mathrm{km}$. The ionospheric current of this amount produces a horizontal mag-

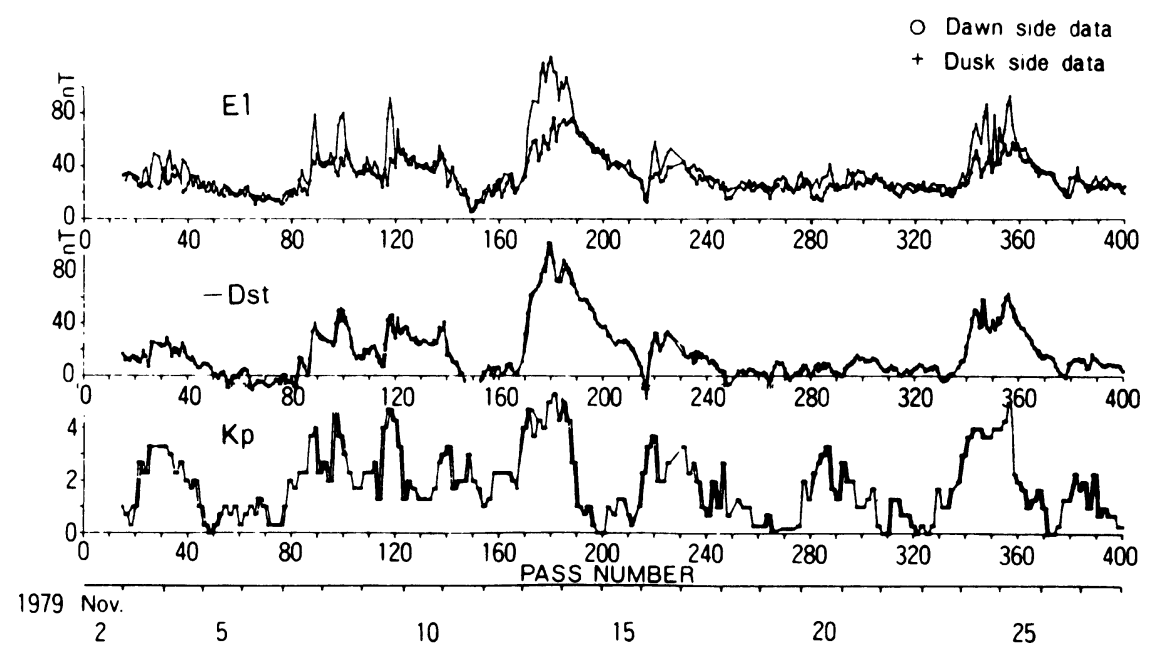

Fig. 9. Comparison of the southward magnetic disturbance field at the MAGSAT level (denoted by E1), $D s t$ and $K p$ index values for the period of $3-$ 27 November 1979. The dawn-dusk asymmetry in E1-values is noticeable during the developing stages of magnetic storms (after Yanagisawa, 1984). 


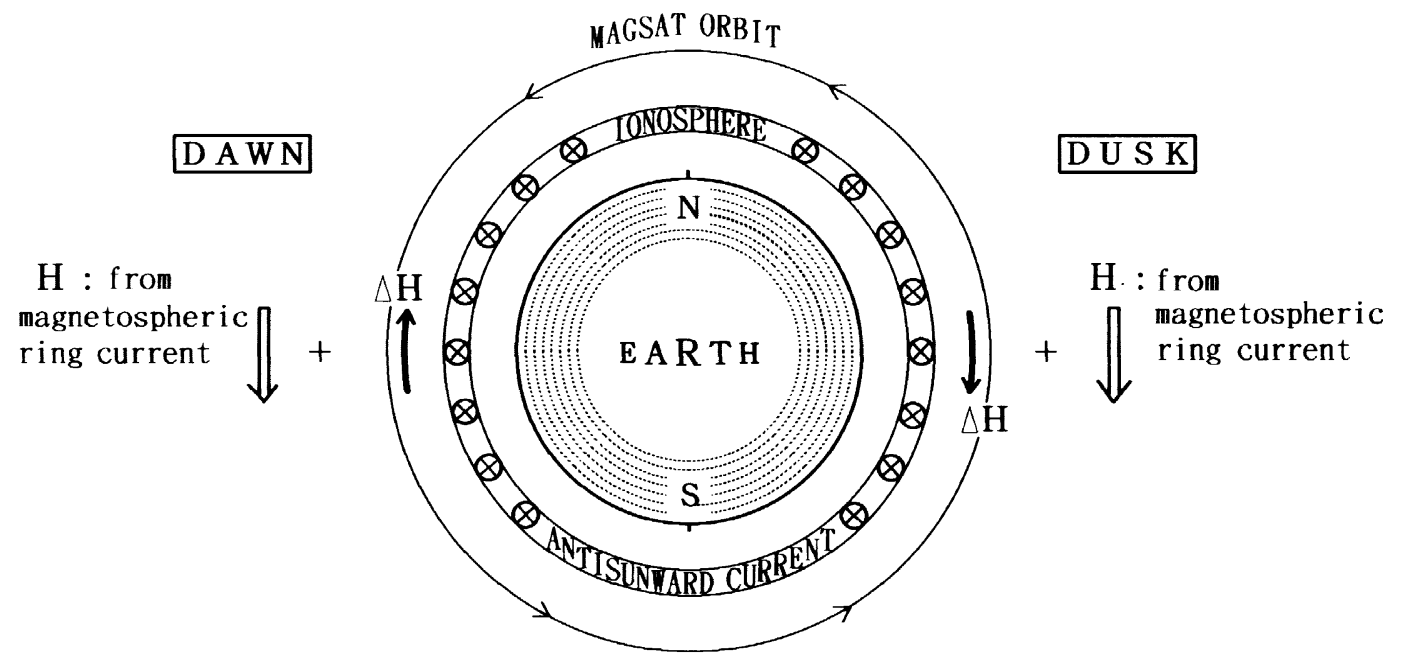

Typical pattern of $B_{t}$ curve

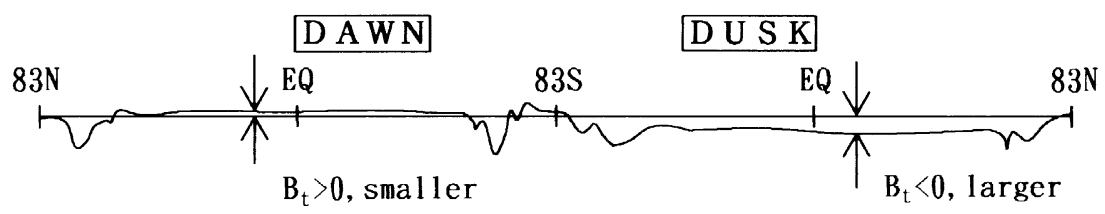

Fig. 10. Dawn-dusk asymmetry of the resultant magnetic field observed at the MAGSAT level, which consists of $\Delta H$ produced by the antisunward current flowing in the ionosphere and a quasi-uniform southward $H$ originated from magnetospheric ring current. A typical pattern of the asymmetric $B_{\mathrm{t}}$ curve shown at the bottom is for a MAGSAT orbit of $\mathrm{N} \rightarrow \mathrm{S} \rightarrow \mathrm{N}$ seen from the sun, in contrast to the illustration in Fig. 3 .

netic field of approximately 30 nT northward on the dawn side, and southward on the dusk side, resulting in the total $\Delta H$-asymmetry of $60 \mathrm{nT}$ above the ionosphere. On the other hand, no magnetic field is produced on the ground by the antisunward current flowing in the ionosphere surrounding the earth (Fukushima, 1976).

It seems therefore to be quite reasonable to surmise that the occasional enhancement of the dawn-dusk asymmetry in E1 up to 40-80 nT shown in Fig. 9 will be attributable to a rapid development and subsequent decay of a partial ring current system (with the current intensity of about $2 \cdot 10^{6} \mathrm{~A}$ or so) in the early phase of magnetic storms. However, it is of course necessary to carry out a quantitative estimation on the pattern of antisunward current flowing in the ionosphere and associated magnetic effect, with reasonable models for the ionospheric conductivity over the earth.

In fact the height-integrated conductivity of the ionosphere is greater on the afternoon side than on the morning side, so that the antisunward current in the ionosphere is stronger on the afternoon side. This dawn-dusk asymmetry of the antisunward current in the ionosphere produces a northward magnetic field at middle and low latitudes on the ground on the afternoon side, and a southward magnetic field on the morning side, in the opposite direction to the magnetic field produced above the ionosphere. Iyemori and Rao (1996) reported that the $D s t$ field (based on the $H$-decrease observed on the ground at some selected middlelatitude stations) shows a tendency to recover storm-time worldwide $H$-decrease after substorm onsets (identified from the sudden $A L$-index drop, pi 2 onsets, or low-latitude posi- tive bay commencements). Apparent contradiction between the $H$-decrease during storms and its recovery during substorms might be reasonably interpreted with the antisunward current in the ionosphere (a segment of a partial ring current system), whose associated magnetic field is in the opposite direction on the ground (below the ionosphere) and at the MAGSAT level (above the ionosphere).

\section{Conclusions}

Ampère's law was applied to the data obtained by the MAGSAT satellite to study the total intensity of space current penetrating through the dawn-dusk plane enclosed by the satellite orbit. The following results were obtained through our analysis, i.e.:

(1) The component of magnetic field in the direction of MAGSAT orbit (denoted by $B_{\mathrm{t}}$ in this paper) shows very often (or sometimes persistently) minor or moderate fluctuations in the polar regions, in particular well inside the auroral oval, even on extremely quiet days without increasing $K p$ - or $A E$-indices. These minor disturbances detected above the ionosphere are attributable to the magnetic field (of toroidal nature) associated with field-aligned currents into or out of the ionosphere. The quiet-day $B_{\mathrm{t}}$ fluctuations are of greater magnitude in the summer hemisphere than in the winter hemisphere.

(2) On disturbed days or during magnetic substorms, $B_{\mathrm{t}^{-}}$ curves along the MAGSAT orbit show distinct horn-like excursions over the auroral oval. The $B_{\mathrm{t}}$-deviations for successive orbits (with 1.5 hours time intervals) indicate that the eastward electrojet on the dusk side seems to be 
rather stable, particularly in the winter season, in comparison with the westward electrojet on the morning side showing frequent sporadic changes.

(3) The line-integration of $B_{\mathrm{t}}$-values over the MAGSAT orbit enables us with Ampère's law to know the total intensity of electric currents penetrating the plane enclosed by the MAGSAT orbit (denoted by $I$ in this paper).

(4) The calculated $I$-value for quiet days is as low as the order of $10^{5} \mathrm{~A}$, with a small-range UT variation, slightly sunward over 10-19 h UT and antisunward over 01-07 h UT. However, it is necessary to check the accuracy of MGST(4/81) model before we discuss such a weak space current fixed to the rotating earth.

(5) In disturbed conditions, the calculated $I$-values become one order of magnitude greater, i.e., to a few times $10^{6}$ A, always antisunward, with their intensity nearly in proportion to the simultaneous $A E$-index values.

(6) The space current under the MAGSAT seems to be reasonably interpreted as a return current of the partial ring current in the magnetosphere; the return current starts as a bundle of field-aligned currents from the dayside magnetosphere to the polar ionosphere, where it is converted to an antisunward Pedersen current in the lower ionosphere, and it leaves the ionosphere as a bundle of field-aligned currents back to the partial ring current in the night-side magnetosphere.

(7) The dawn-dusk asymmetry of the $H$-decrease observed by MAGSAT is enhanced every time at the initial stage of magnetic storms or during substorms. This asymmetry seems to be caused by a rapid development and decay of a partial ring current in the afternoon-side magnetosphere, and the ionospheric segment of the partial ring current system seems to be responsible for the observed dawn-dusk asymmetry above the ionosphere, because the antisunward ionospheric current produces a southward magnetic field at the MAGSAT level in the dusk meridian, and a northward field in the dawn meridian, so as to intensify the dawn-dusk asymmetry. Our interpretation seems also to contribute to understand the difference between magnetic signatures observed on the ground and at the satellite level.

(8) We expect that some future satellites for world magnetic surveys (such as Danish Ørsted satellite) will be useful for finding the space current under the satellite orbit for various local-time meridians, which are necessary for us to construct a more comprehensive picture for the spatial structure of the partial ring current system during magnetic storms and substorms.

Acknowledgments. The MAGSAT data used in this study were supplied from NASA in 1980/81 to the Japanese MAGSAT Investigation Team for the Statement of Work M-43, and their copies were distributed inside Japan from the National Institute of Polar Research. We used the tapes supplied to the Data Analysis Center for Geomagnetism and Spacemagnetism in Kyoto University. These tapes were copied at the Data Processing Center of Kyoto University and analysed at the Computer Center of Kyushu University. We are much obliged to these organizations and their staff. The geomagnetic $A E$ indices were taken from the type compiled by the Data Analysis Center of Kyoto University. The authors wish to thank the referees for their kind advice to improve the manuscript of this paper.

\section{References}

Barfield, J. N., N. A. Saflekos, R. E. Sheehan, R. L. Carovillano, T. A. Potemra, and D. Knecht, Three-dimensional observations of Birkeland currents, J. Geophys. Res., 91, 4393-4403, 1986.

Bythrow, P. F. and T. A. Potemra, The relationship of total Birkeland currents to the merging electric field, Geophys. Res. Lett., 10, 573-576, 1983.

Crooker, N. U. and R. L. McPherron, On the distinction between the auroral electrojet and partial ring current systems, J. Geophys. Res., 77, 6886-6889, 1972.

Crooker, N. U. and G. L. Siscoe, A study of the geomagnetic disturbance field asymmetry, Radio Sci., 6, 495-501, 1971.

Crooker, N. U. and G. L. Siscoe, Birkeland currents as the cause of the low-latitude asymmetric disturbance field, J. Geophys. Res., 86, 11,20111,210, 1981.

Cummings, W. D., Asymmetric ring currents and the low-latitude disturbance daily variation, J. Geophys. Res., 71, 4495-4503, 1966.

Engebretson, M. J., L. J. Cahill, Jr., T. A. Potemra, L. J. Zanetti, R. L. Arnoldy, S. B. Mende, and T. J. Rosenberg, On the relationship between morning sector irregular magnetic pulsations and field aligned currents, J. Geophys. Res., 89, 1602-1612, 1984.

Fujii, R. and T. Iijima, Control of the ionospheric conductivities on largescale Birkeland current intensities under geomagnetic quiet conditions, J. Geophys. Res., 92, 4505-4513, 1987.

Fukushima, N., Generalized theorem for no ground magnetic effect of vertical currents connected with Pedersen currents in the uniformconductivity ionosphere, Rep. Ionos. Space Res. Japan, 30, 35-40, 1976.

Fukushima, N. and Y. Kamide, Partial ring current models for worldwide geomagnetic disturbances, Rev. Geophys. Space Phys., 11, 795-853, 1973

Hughes, T. J., D. D. Wallis, J. R. Burrows, and M. D. Wilson, Model predictions of magnetic perturbations observed by MAGSAT in dawndusk orbit, Geophys. Res. Lett., 9, 357-360, 1982.

Iijima, T. and T. A. Potemra, Large-scale characteristics of field-aligned currents associated with substorms, J. Geophys. Res., 83, 599-615, 1978.

Iijima, T. and T. Shibaji, Global characteristics of northward IMFassociated (NBZ) field-aligned currents, J. Geophys. Res., 92, 24082424, 1987.

Iijima, T., N. Fukushima, and R. Fujii, Transverse and parallel geomagnetic perturbations over the polar regions observed by MAGSAT, Geophys. Res. Lett., 9, 369-372, 1982.

Iijima, T., T. A. Potemra, L. J. Zanetti, and P. F. Bythrow, Large-scale Birkeland currents in the dayside polar region during strongly northward IMF: A new Birkeland current system, J. Geophys. Res., 89, 7441$7452,1984$.

Iyemori, T., Storm-time magnetospheric currents inferred from midlatitude geomagnetic field variations, J. Geomag. Geoelectr., 42, 1249$1265,1990$.

Iyemori, T. and D. R. K. Rao, Decay of the Dst field of geomagnetic disturbance after substorm onset and its implication to storm-substorm relation, Ann. Geophys., 14, 608-618, 1996.

Iyemori, T., T. Ikeda, and A. Nakagawa, Amplitude distribution of smallscale magnetic fluctuations over the polar ionosphere observed by Magsat, J. Geophys. Res., 90, 12,335-12,339, 1985.

Kamide, Y. and N. Fukushima, Positive geomagnetic bays in evening high-latitudes and their possible connection with partial ring current, Rept. Ionos. Space Res. Japan, 26, 79-101, 1972.

Kamide, Y., D. S. Evans, and J. C. Cain, A comparison of field-aligned current signatures simultaneously observed by the MAGSAT and TIROS/NOAA spacecraft, J. Geomag. Geoelectr., 36, 521-527, 1984.

Kan, J. R., T. Iijima, and S.-I. Akasofu, A model of coupled radial and azimuthal current loops associated with substorms, J. Geophys. Res., 95, 21,291-21,295, 1990.

Klumpar, D. M. and D. M. Greer, A technique for modeling the magnetic perturbations produced by field-aligned current systems, Geophys. Res. Lett., 9, 361-364, 1982.

Lanchester, B. S. and D. D. Wallis, Magnetic field disturbances over auroral arcs observed from Spitsbergen, J. Geophys. Res., 90, 24732480, 1985.

Langel, R. A., The magnetic earth as seen from MAGSAT, initial results, Geophys. Res. Lett., 9, 239-242, 1982.

Langel, R. A., G. Ousley, J. Berbert, J. Murphy, and M. Settle, The 
MAGSAT mission, Geophys. Res. Lett., 9, 243-245, 1982.

Maeda, H., T. Iyemori, T. Araki, and T. Kamei, New evidence of a meridional current system in the equatorial ionosphere, Geophys. Res. Lett., 9, 337-340, 1982.

Maeda, H., T. Kamei, T. Iyemori, and T. Araki, Geomagnetic perturbations at low latitudes observed by Magsat, J. Geophys. Res., 90, 24812486, 1985.

Potemra, T. A., L. J. Zanetti, P. F. Bythrow, A. T. Y. Lui, and T. Iijima, $B_{y}$-dependent convection patterns during northward interplanetary magnetic field, J. Geophys. Res., 89, 9753-9760, 1984.

Suzuki, A. and N. Fukushima, Sunward or anti-sunward electric current in space below the MAGSAT level, Geophys. Res. Lett., 9, 345-347, 1982.

Suzuki, A. and N. Fukushima, Anti-sunward space current below the MAGSAT level during magnetic storms, J. Geomag. Geoelectr., 36 493-506, 1984

Suzuki, A., M. Yanagisawa, and N. Fukushima, Antisunward space current below the Magsat level during magnetic storms and its possible connection with partial ring current in the magnetosphere, J. Geophys. Res., 90(B3), 2465-2471, 1985.

Wallis, D. D., J. R. Burrows, T. J. Hughes, and M. D. Wilson, Eccentric dipole coordinates for MAGSAT data presentation and analysis of external current effects, Geophys. Res. Lett., 9, 353-356, 1982.

Yamada, Y., M. Takeda, and T. Araki, Field-aligned currents during northward interplanetary magnetic field, Memoirs Kakioka Mag. Obs.,
23, 39-51, 1990 (in Japanese with English abstract).

Yamauchi, M. and T. Araki, The interplanetary magnetic field $B_{y}$-dependent field-aligned current in the dayside polar cap under quiet conditions, J. Geophys. Res., 94, 2684-2690, 1989.

Yanagisawa, M., Derivation of crustal magnetic anomalies from MAGSAT, The Inst. Space and Astronautical Sci. Rep. No. 609, 1-65, 1984

Zanetti, L. J. and T. A. Potemra, Correlated Birkeland current signatures from the TRIAD and MAGSAT magnetic field data, Geophys. Res. Lett., 9, 349-352, 1982.

Zanetti, L. J., T. A. Potemra, and M. Sugiura, Evaluation of high latitude disturbances with MAGSAT (The importance of the MAGSAT geomagnetic field model), Geophys. Res. Lett., 9, 365-368, 1982.

Zanetti, L. J., W. Baumjohann, and T. A. Potemra, Ionospheric and Birkeland current distributions inferred from the MAGSAT magnetometer data, J. Geophys. Res., 88, 4875-4884, 1983.

Zanetti, L. J., T. A. Potemra, T. Iijima, W. Baumjohann, and P. F. Bythrow, Ionospheric and Birkeland current distributions for northward interplanetary magnetic field: inferred polar convection, $J$. Geophys. Res., 89, 7453-7458, 1984.

A. Suzuki (e-mail: suzuki@que.phys.saga-u.ac.jp) and N. Fukushima 